\title{
Disturbed homocysteine metabolism is associated with cancer
}

\author{
Tauheed Hasan', Reetika Arora', Aniket Kumar Bansal', Reshmee Bhattacharya', Gurumayum Suraj Sharma and \\ Laishram Rajendrakumar Singh ${ }^{1}$
}

\begin{abstract}
Hyperhomocysteinemia/Homocysteinuria is characterized by an increased level of toxic homocysteine in the plasma. The plasma concentration of homocysteine is $5-15 \mu \mathrm{mol} / \mathrm{L}$ in healthy individuals, while in hyperhomocysteinemic patients, it can be as high as $500 \mu \mathrm{mol} / \mathrm{L}$. While increased homocysteine levels can cause symptoms such as osteoporosis and eye lens dislocation, high homocysteine levels are most closely associated with cardiovascular complications. Recent advances have shown that increased plasma Hcy is also a fundamental cause of neurodegenerative diseases (including Alzheimer's disease, Parkinson's disease, and dementia), diabetes, Down syndrome, and megaloblastic anemia, among others. In recent years, increased plasma homocysteine has also been shown to be closely related to cancer. In this review, we discuss the relation between elevated plasma Hcy levels and cancer, and we conclude that disturbed homocysteine metabolism is associated with cancer. Future clinical perspectives are also discussed.
\end{abstract}

\section{Introduction}

Homocystinuria is an inborn error in the metabolic pathways of sulfur-containing amino acids and is characterized by an increase in the level of toxic homocysteine (Hcy) in the serum ${ }^{1}$. Mutations in cystathionine beta synthase (CBS), an enzyme present at the branch point between the trans-sulfuration and remethylation pathways, are the basic cause of homocysteinemia. The term "hyperhomocysteinemia" is also used to describe the elevated Hcy serum level due to other genetic (CBS-independent) and environmental factors ${ }^{2}$. In a normal, healthy individual, the serum Hcy level is between $5-15 \mu \mathrm{M}$, but it can increase to $50 \mu \mathrm{M}$ in mild cases and to $500 \mu \mathrm{M}$ in severe cases of homocysteinemia (de Koning, Werstuck et al. 2003). This hyperhomocysteinemic condition is closely related to many disease conditions (Table 1). It is believed that increased homocysteine levels lead to various cardiovascular complications (Table 1$)^{3,4}$ If the Hcy level is left uncontrolled, patients ultimately die of stroke ${ }^{5}$. Further studies have also

Correspondence: Laishram Rajendrakumar Singh (lairksingh@gmail.com)

${ }^{1}$ Dr. B. R. Ambedkar Center for Biomedical Research, University of Delhi, Delhi 110007, India revealed that elevated plasma Hcy level is one of the key factors associated with neurodegeneration, diabetes, Down syndrome, neural tube defects, and megaloblastic anemia (see Table 1$)^{2,4,6-9}$. Hyperhomocysteinemia has also been connected to various other clinical complications, including ectopic lentis, scoliosis, megaloblastic anemia, knocked knees, long limbs, and arachnodactyly, among others (Table 1$)^{4,10-12}$. Recent advances have proven that there is a close link between hyperhomocystinuria and cancer (see Fig. 1). First, higher levels of plasma homocysteine have been observed cancer patients, and venous thromboembolism (VTE) is the second most common cause of death in cancer patients. Second, several polymorphisms in the enzymes involved in the Hcy detoxification pathways (the transsulfuration and remethylation) have close clinical ties to several cancer types ${ }^{13-23}$. Third, folate, which is pivotal for cell proliferation, has an inverse relation with Hcy. Fourth, Hcy has also been proposed as a potential tumor biomarker for a variety of cancers ${ }^{24}$. In this review, we have systematically discussed these important key events in detail and revealed that defects in Hcy metabolism may lead to cancer. Future clinical perspectives have also been described. 


\section{I (a) Low folate levels help build plasma Hcy}

Homocysteine is a sulfur-containing, nonprotein, toxic amino acid found in the pathway for the interconversion of two amino acids: methionine and cysteine. Homocysteine is metabolized via two different pathways: remethylation

Table 1 Homocysteinemia and its associated disorders

\begin{tabular}{|c|c|c|}
\hline Complication & Associated diseases & References \\
\hline \multirow{6}{*}{ Cardiovascular diseases } & Thromboembolism & 130,131 \\
\hline & Coronary artery & 132 \\
\hline & Atherosclerosis & 133,134 \\
\hline & Vascular dementia & 135,136 \\
\hline & Congenital heart defects & 137,138 \\
\hline & Stroke & 139,140 \\
\hline \multirow[t]{5}{*}{ Neurodegeneration } & Alzheimer's & 6 \\
\hline & Parkinson & 141,142 \\
\hline & Schizophrenia & 143,144 \\
\hline & Dementia & 145,146 \\
\hline & Depression & 147,148 \\
\hline Diabetes & - & 149,150 \\
\hline Down's syndrome & - & 151 \\
\hline Megaloblastic anemia & - & 152 \\
\hline \multirow[t]{7}{*}{ Other diseases } & Neural tube defects & 55 \\
\hline & Nonsyndromic oral cleft & 153 \\
\hline & Ectopic lentis & $6,139,140$ \\
\hline & Scoliosis & 154 \\
\hline & Knocked knees & 154 \\
\hline & Long limbs & 154 \\
\hline & Arachnodactyly & 154 \\
\hline Cancer & Refer to Fig. 3 & \\
\hline
\end{tabular}

and trans-sulfuration ${ }^{25,26}$. When there is an excess of cellular methionine, the trans-sulfuration pathway plays a crucial role in Hcy metabolism, converting Hcy to cystathionine via CBS, which requires pyridoxal $5^{\prime}$-phosphate as a co-factor ${ }^{25,27}$. When the cellular methionine level is low, Hcy is remethylated back to methionine in a betaine- or folate-dependent reaction. In the betaine-dependent pathway, the enzyme betaine-homocysteine S-methyltransferase (BHMT) $)^{28,29}$ catalyzes the incorporation of a methyl group from betaine into homocysteine to form methionine. In the folate-dependent pathway, Hcy acquires a methyl group from N-5-methyltetrahydrofolate with the help of 5methyltetrahydrofolate-homocysteine methyltransferase (MTR) (also known as methionine synthase). Methionine synthase requires vitamin B12 for its functionality, and the reaction also involves recycling of tetrahydrofolate (from N-5-methyltetrahydrofolate), which may eventually be used for nucleotide biosynthesis ${ }^{30}$. Methionine synthase, therefore, couples the folate and Hcy metabolism pathways (Fig. 2). Since the generation of tetrahydrofolate depends on the input of exogenous folate for folate metabolism (as outlined in Fig. 2), low folate levels ultimately result in substrate limitation for methionine synthase, thereby affecting the remethylation pathway. Thus, low folate levels result in a high plasma Hcy concentration and vice versa.

Many factors that affect the folate level have also been found to disturb the Hcy level. For instance, diets deficient in folate, cobalamin, and vitamin $\mathrm{B}^{31}$ and use of antifolate drugs (including anticonvulsants and other neurological drugs ${ }^{32}$ ) directly increase the plasma Hcy level. Drugs that elevate the Hcy level (e.g., laxatives, diuretics, birth control pills, anti-inflammatory drugs, immune suppressants) also reduce the folic acid levels ${ }^{33-36}$. Other conditions, including alcohol consumption ${ }^{13,18}$, smoking, diabetes, and psoriasis ${ }^{37}$, among others, are responsible for reducing the plasma folate level by affecting the folate level. Therefore, it is important to take folate supplements to restore the depleted Hcy pool.

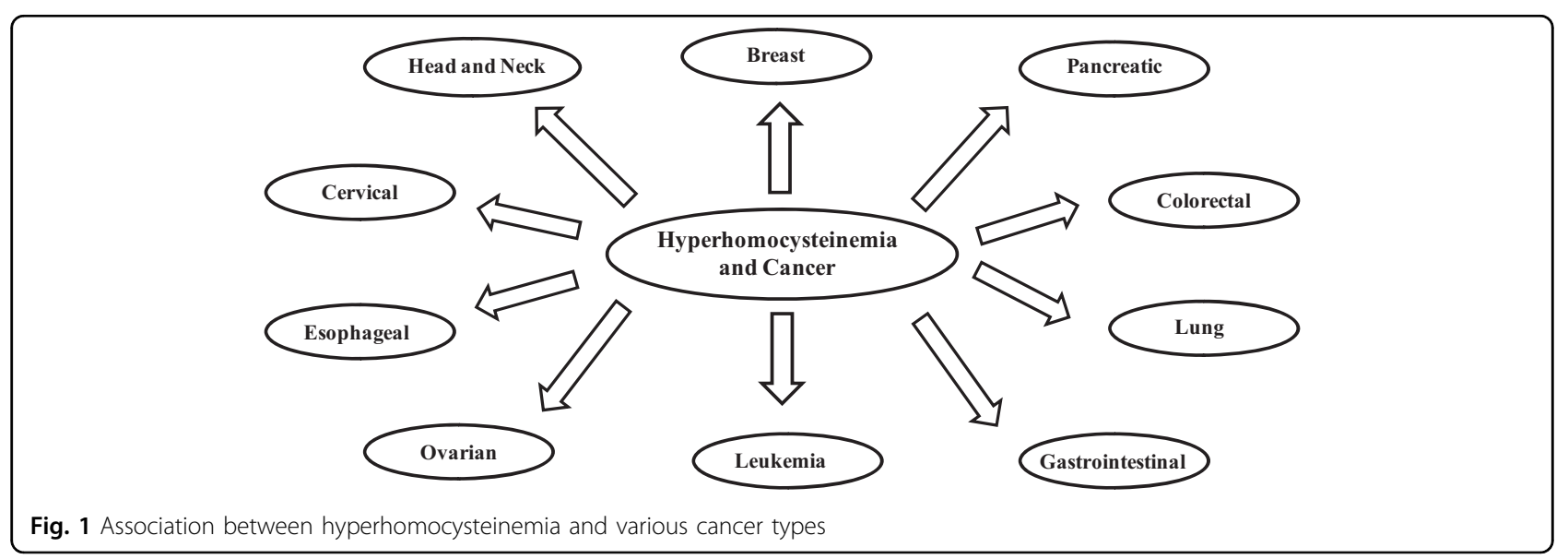




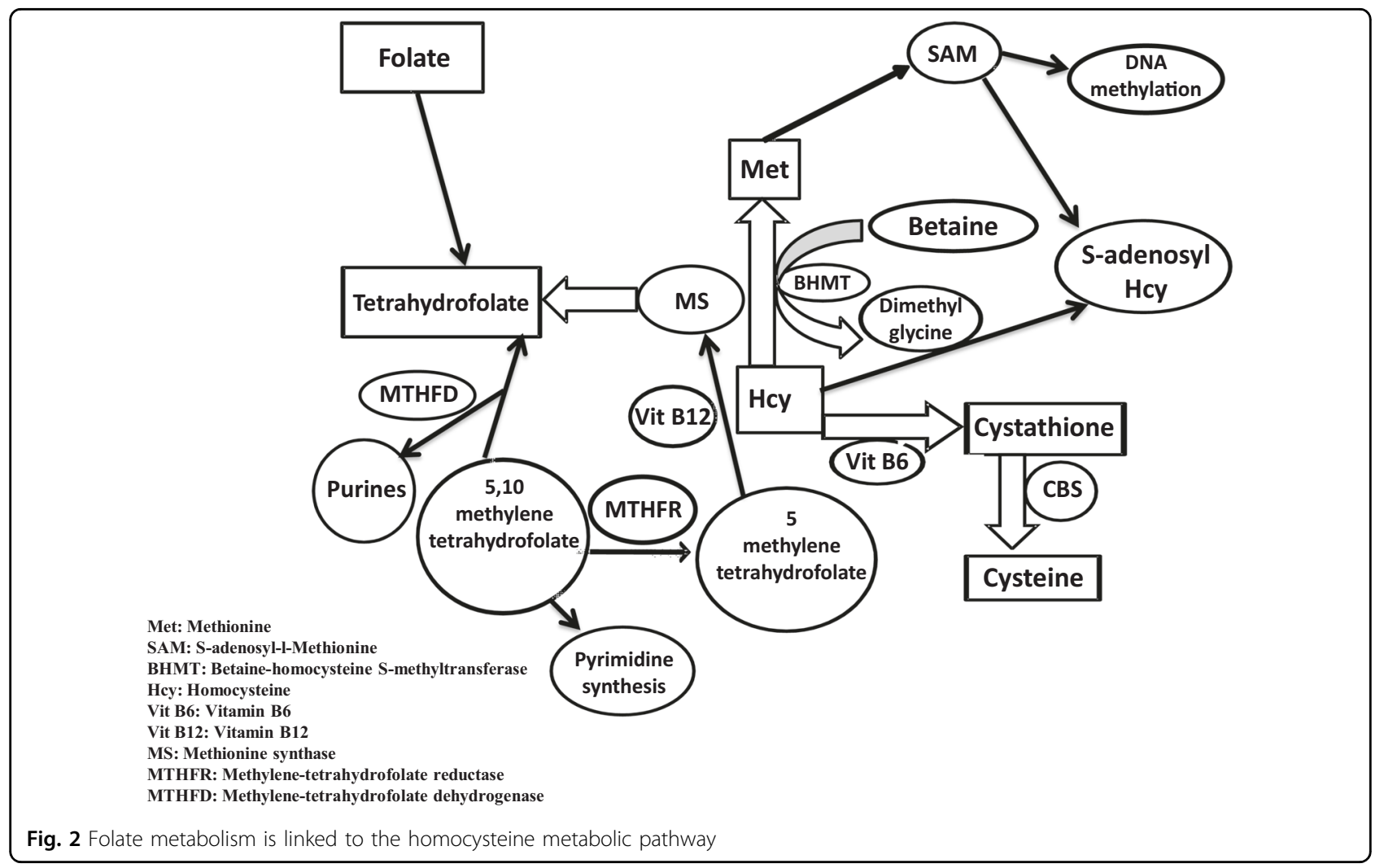

\section{I (b) Low plasma folate levels lead to cancer predisposition}

Folate is not only involved in nucleotide biosynthesis but also required for the conversion of deoxyuridine monophosphate (dUMP) into thymidine monophosphate $^{38}$. Under normal conditions, thymidylate synthetase (TYMS) converts dUMP into thymidine monophosphate using 5,10-methylenetetrahydrofolate (derived from folate) as a methyl group donor. If folate is limiting, dUMP accumulates because its key methyl donor, 5,10-methylenetetrahydrofolate, is absent. These conditions lead to an imbalance in the deoxyribonucleotide pool, and, consequently, there is excessive incorporation of uracil into DNA instead of thymine; this defect is normally repaired by the enzyme uracil DNA glycosylase, which removes the misincorporated uracil from the DNA strand ${ }^{39}$. When the folate concentration is disturbed (due to increased Hcy levels) the DNA glycosylase fails to cope with the DNA repair burden. This situation leads to chromosomal damage, which may then lead malignant transformation in cells. Furthermore, excision repair of uracil residues 12 base pairs apart can lead to double strand breaks, which may increase DNA instability due to relaxed DNA supercoiling and chromosomal remodeling, both of which can cause an increase in malignant transformation. Chromosomal aberrations are also associated with inappropriate differentiation and morphology of lineage-specific cells, features often associated with tumors ${ }^{40}$.

Low plasma folate levels are also linked to cancer is via DNA methylation. DNA methylation is an epigenetic modification that is critical for normal genome regulation and development. Indeed, it is Hcy that is recycled to methionine with the help of methionine synthase. DNA methylation is carried out with the help of a methyl donor, S-adenosyl-1-methionine (SAM), which is obtained from methionine via an ATPdependent reaction catalyzed by S-adenomethyl synthetase ${ }^{41}$. DNA methylation is jointly carried out by three types of DNA methyltransferases (DNMTs) DNMT1, DNMT3a, and DNMT3b on SAM (Fig. 3). Since SAM is generated from 5-methyltetrahydrofolate (5'-MTHF) as shown in Fig. 3, low folate levels limit the substrate availability for methionine synthase, thereby resulting in DNA hypomethylation. DNA hypomethylation leads to decondensation of pericentromeric heterochromatin and the activation of retrotransposon elements $^{42}$. Global genomic hypomethylation has been found in many types of cancer, including prostate metastatic tumors, chronic lymphocytic tumors, and hepatocellular carcinoma. Regional hypomethylation of DNA sequences is also often observed during the early stages of tumorigenesis and in abnormal nonneoplastic tissue, such as hyperplasia ${ }^{43}$. 


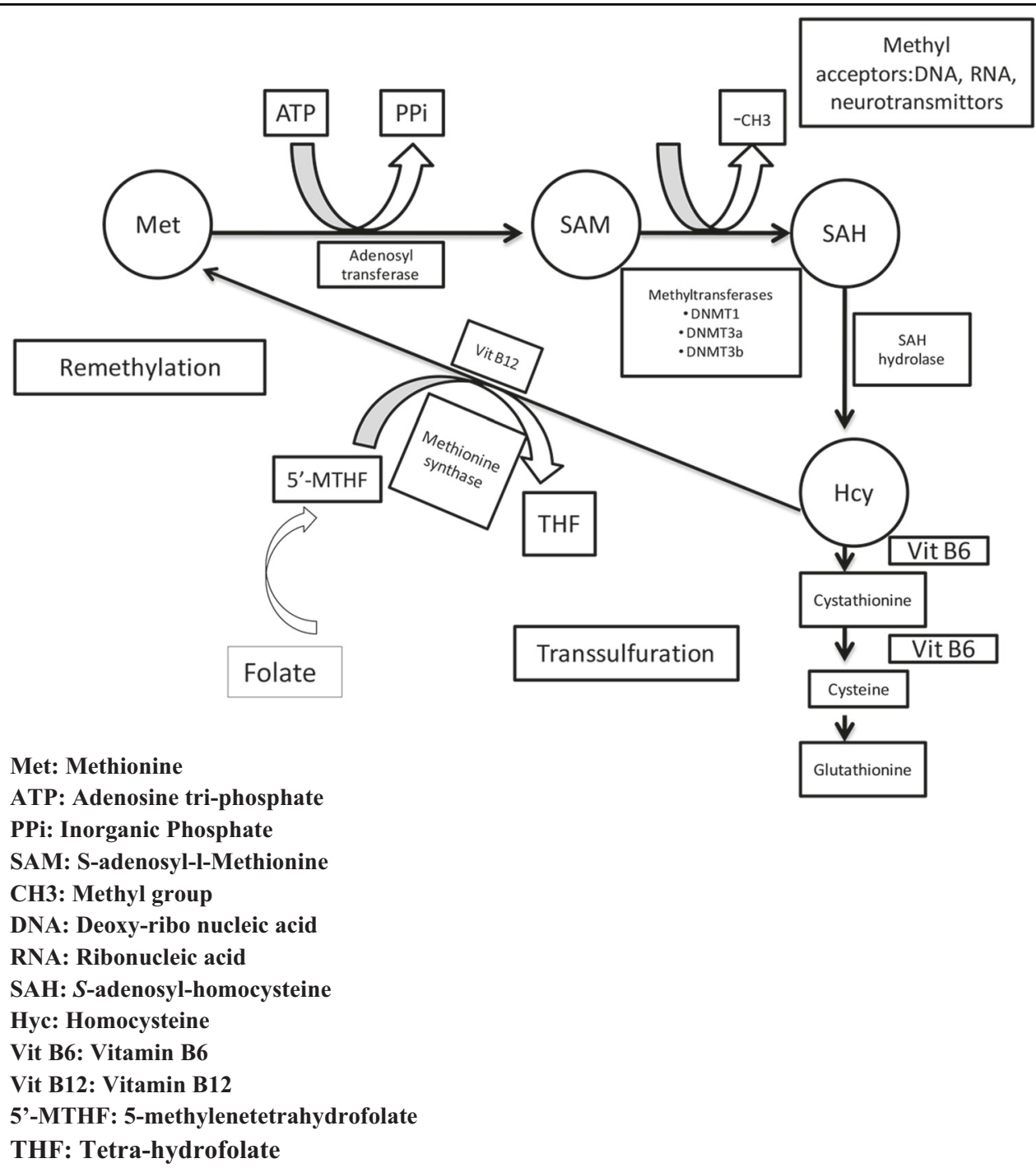

Fig. 3 Low folate levels result in Hypomethylation

\section{I (c) Cancer patients have high plasma Hcy levels}

As mentioned in the earlier sections, there is an inverse relation between plasma Hcy and folate. In cancer patients, the plasma folate level is expected to be low because tumor cells must draw folate from the blood for de novo purine synthesis ${ }^{44,45}$. Interestingly, as shown in Fig. 1, hyperhomocystinuria is associated with several types of cancer. It is also clear from the information in this figure that the causative relationship between homocysteine toxicity and cancer is independent of the organ/ tissue and the type of cancer. Table 2 shows that all cancer types in the advanced stage exhibit high plasma Hcy levels, while there was no significant change in plasma Hcy levels in early stage cancer. Furthermore, once patients are subjected to surgery or chemotherapy, there is also a sharp increase in the plasma Hcy level, leading to a higher frequency of thromboembolic events. Because most commonly used clinical chemotherapeutic agents (such as alkylating agents, antimetabolites, methotrexate, hormones, and antagonists) are anti-folate drugs ${ }^{46}$, their use causes a decrease in the plasma folic acid concentration. In another development, it has also been shown that older cancer patients are at a higher risk of developing hyperhomocysteinemia than are younger patients ${ }^{47}$.

There is no clear explanation for why the Hcy levels vary between early and late stage cancer. However, we speculate that cells in the early stage might not secrete Hcy, as it facilitates the proliferation process of cancer cells $^{48}$. Studies have shown that increased homocysteine levels lead to increased cellular proliferation in Caco- 2 cell lines. This enhanced proliferation can be reversed by folate supplementation in the culture medium or by supplementation with its downstream metabolites, such 
Table 2 Polymorphisms detected in genes involved in homocysteine metabolism

\begin{tabular}{|c|c|c|c|c|c|}
\hline Gene & Polymorphisms & $\begin{array}{l}\text { Amino acid } \\
\text { change }\end{array}$ & Cancer type & OR values & References \\
\hline \multirow{11}{*}{$\begin{array}{l}\text { Methylene-tetrahydrofolate reductase } \\
\text { (MTHFR) }\end{array}$} & \multirow[t]{6}{*}{$677 \mathrm{C}->\mathrm{T}$} & \multirow[t]{6}{*}{ A226V } & Endometrial carcinoma & 1.10 & 155 \\
\hline & & & $\begin{array}{l}\text { Esophageal squamous cell } \\
\text { carcinoma (SCC) }\end{array}$ & 1.47 & 156 \\
\hline & & & Breast cancer & $\begin{array}{l}1.00^{\mathrm{a}} / 1.12 / \\
1.00^{\mathrm{a}}\end{array}$ & $15,99,157$ \\
\hline & & & Acute lymphocytic leukemia (ALL) & $0.99 / 0.23$ & 87 \\
\hline & & & Prostate cancer & 0.78 & 158 \\
\hline & & & Colorectal cancer & $\begin{array}{l}1.78 / 1.00^{\mathrm{a}} / \\
0.76\end{array}$ & $85,159-161$ \\
\hline & \multirow[t]{3}{*}{$1298 \mathrm{~A}->\mathrm{C}$} & \multirow[t]{3}{*}{ E443A } & Prostate cancer & 0.58 & 79 \\
\hline & & & Acute myeloid leukemia & $0.33 / 1.00$ & 87,162 \\
\hline & & & Endometrial cancer & 0.88 & 155 \\
\hline & \multirow[t]{2}{*}{ 1793G->A } & \multirow[t]{2}{*}{ R1793E } & Colorectal cancer & 0.17 & 163 \\
\hline & & & Acute myeloid leukemia & 1.00 & 162 \\
\hline \multirow[t]{4}{*}{ Methionine synthase reductase (MTRR) } & \multirow[t]{4}{*}{$66 \mathrm{~A}->\mathrm{G}$} & \multirow[t]{4}{*}{ I22M } & Leukemia & $1.00^{\mathrm{a}}$ & 164,165 \\
\hline & & & Colorectal cancer & $2.77 / 1.07$ & $18,165,166$ \\
\hline & & & Gastric cancer & $0.74 / 1.39$ & 167,168 \\
\hline & & & Breast cancer & 4.45 & 169 \\
\hline \multirow[t]{10}{*}{ Methionine synthase (MTR) } & \multirow[t]{10}{*}{$2756 \mathrm{~A}->\mathrm{G}$} & \multirow[t]{10}{*}{ D919G } & Head and neck carcinoma & 1.10 & 170 \\
\hline & & & Colorectal cancer & $\begin{array}{l}1.03 / 0.65 / \\
2.04\end{array}$ & $161,170,171$ \\
\hline & & & Lung cancer & 1.34 & 172 \\
\hline & & & Hepatocellular carcinoma & 1.01 & 170,173 \\
\hline & & & Cervical cancer & 0.27 & 14 \\
\hline & & & Glioblastoma multiforme & $1.00^{\mathrm{a}}$ & 174 \\
\hline & & & Breast cancer & $1.00^{\mathrm{a}}$ & 99 \\
\hline & & & Squamous cell carcinoma & $1.00^{\mathrm{a}}$ & 98 \\
\hline & & & Gastric cancer & $1.06 / 1.35$ & $168,170,175$ \\
\hline & & & Pancreatic cancer & $1.08 / 3.35$ & 170,176 \\
\hline \multirow{5}{*}{$\begin{array}{l}\text { Methylene-tetrahydrofolate dehydrogenase } \\
\text { (MTHFD1) }\end{array}$} & \multirow[t]{2}{*}{$1958 \mathrm{G}->\mathrm{A}$} & \multirow[t]{2}{*}{ A653G } & Gastric cancer & 2.05 & 102 \\
\hline & & & Leukemia & 0.80 & 177 \\
\hline & \multirow[t]{3}{*}{$401 \mathrm{G}->\mathrm{A}$} & \multirow[t]{3}{*}{ R134K } & Gastric cancer & 1.43 & 102 \\
\hline & & & Leukemia & 0.89 & 177 \\
\hline & & & Ovarian cancer & 0.97 & 178 \\
\hline \multirow{5}{*}{$\begin{array}{l}\text { Betaine-homocysteine methyltransferase } \\
\text { (BHMT) }\end{array}$} & \multirow[t]{5}{*}{$742 \mathrm{G}->\mathrm{A}$} & \multirow[t]{5}{*}{ R239Q } & Squamous cell carcinoma & 1.07 & 179 \\
\hline & & & Breast cancer & $0.98 / 0.12$ & 111,180 \\
\hline & & & Uterine carcinoma & 0.64 & 181 \\
\hline & & & Ovarian cancer & 1.01 & 182 \\
\hline & & & Colorectal adenoma & 1.09 & 183 \\
\hline
\end{tabular}


Table 2 continued

\begin{tabular}{|c|c|c|c|c|c|}
\hline Gene & Polymorphisms & $\begin{array}{l}\text { Amino acid } \\
\text { change }\end{array}$ & Cancer type & OR values & References \\
\hline & & & Liver cancer & 0.98 & 184 \\
\hline & $595 G->A$ & G199S & - & & \\
\hline & $716 \mathrm{G}->\mathrm{A}$ & Q239R & - & & \\
\hline & $1218 \mathrm{G}->\mathrm{T}$ & Q406H & - & & \\
\hline \multirow[t]{10}{*}{ Cystathionine $\beta$-synthase (CBS) } & $833 \mathrm{~T}->\mathrm{C}$ & $1278 \mathrm{~T}$ & - & & \\
\hline & $699 \mathrm{C}->\mathrm{T}$ & Y233Y & - & & \\
\hline & $1080 \mathrm{C}->\mathrm{T}$ & A360A & - & & \\
\hline & $572 C->T$ & T191M & - & & \\
\hline & $139 C->T$ & S466L & - & & \\
\hline & $502 \mathrm{G}->\mathrm{A}$ & V168M & - & & \\
\hline & 797G- > A & R266K & - & & \\
\hline & $1150 \mathrm{~A}->\mathrm{G}$ & K384E & - & & \\
\hline & $341 C->T$ & A114V & - & & \\
\hline & 919G->A & G307S & - & & \\
\hline \multirow[t]{5}{*}{ TCN 2} & $776 \mathrm{G}>C$ & R259P & Colorectal adenoma & 0.753 & 183 \\
\hline & & & Colorectal cancer & 1.137 & 185 \\
\hline & & & Glioblastoma & 1.028 & 174 \\
\hline & & & $\begin{array}{l}\text { Primary central nervous system } \\
\text { lymphoma }\end{array}$ & 1.338 & 186 \\
\hline & & & Ovarian cancer & 1.389 & 182 \\
\hline \multirow[t]{3}{*}{ TYMS } & TS 3́-UTR & - & Esophageal cancer & 0.73 & 187 \\
\hline & & - & Stomach cancer & 1.12 & 187 \\
\hline & TSER & - & Breast cancer & 1.09 & 187 \\
\hline
\end{tabular}

${ }^{\text {a }}$ Papers that reported no association have been given the value of 1.00

as $5-\mathrm{MTHF}^{49}$. However, advanced-stage cancer cells might secrete Hcy because a very high Hcy concentration might also be cytotoxic to the cancer cells. Therefore, it may be important for proliferating cells to maintain an optimum Hcy concentration. This speculation, however, requires further experimental validation.

\section{I (d) Cancer patients develop thromboembolisms due to Hcy toxicity}

One major symptom of hyperhomocysteinemia is the formation of venous thromboembolism (VTE). VTE is the most frequent complication and second most common cause of death among cancer patients ${ }^{50}$. Advanced-stage cancer patients develop both hyperhomocysteinemia and VTE. Alternatively, in early cancer patients (without homocysteinuria), VTE is absent ${ }^{51}$. Indeed, the advancedstage cancer patients have a greater risk for developing VTE, with a frequency of $5-15 \%{ }^{51,52}$ (in comparison, the risk for the normal population is $0.1 \%$ ). Postchemotherapy cancer patients (who are known to be at risk for homocystinuria) account for $13 \%$ of the total pool of VTE patients $^{53}$. In postsurgery patients, their susceptibilities to embolism and thrombosis are increased three-fold and two-fold, respectively ${ }^{54}$. Use of central venous catheters and hormonal adjuvant therapy (e.g., Tamoxifen) also predisposes patients to $\mathrm{VTE}^{51}$ due to increased plasma Hcy levels. Thus, there is a close link between cancer and Hcy-induced development of VTE.

The mechanism underlying the cancer-related thrombosis induced by elevated $\mathrm{Hcy}^{55}$ is complex and not well understood. However, it has been thought to result from endothelial disturbances caused by the formation of Hcymediated free-radicals ${ }^{56}$. Hcy is a pro-oxidant, and the formation of Hcy-Hcy dimers and Hcy-protein adducts that help to generate free radicals are well established. Hcy can also form a more highly reactive compound called homocysteine thiolactone. Homocysteine thiolactone has been known to form covalent adducts with 
lysine or arginine residues in proteins, resulting in the formation of insoluble toxic protein aggregates or amyloids ${ }^{2,57,58}$. The deposition of such aggregates in the blood or heart may, therefore, impede normal heart function and physiology. Furthermore, modification of hemostatic proteins (via N-homocysteinylation or S-homocysteinylation) has also been reported to impede $\mathrm{NO}$ metabolism, which may cause biotoxicity in endothelial cells $^{59}$. Hcy also inhibits thrombomodulin and Protein Cdependent inactivation of Factor $\mathrm{V}_{\mathrm{a}}{ }^{60}$ therefore, blood coagulation is enhanced in the presence of Hcy. Furthermore, Hcy limits the secretion of nitric oxide (NO), leading to increased platelet aggregation and decreased antithrombic activities in the endothelial cells ${ }^{61,62}$.

\section{I (e) Allelic polymorphisms in sulfur metabolism genes and associated risk of cancer}

Various case control and cohort studies ${ }^{63-70}$ have shown that mutations and polymorphisms exist in genes involved in homocysteine metabolism (MTHFR, CBS, MTRR, MTR, MTHFD, BHMT, TYMS, TCN 2). Polymorphic alleles of these genes were found to be linked with neural tube defects ${ }^{71}$ and/or vascular thromboembolism $^{72,73}$, which are symptoms of hyperhomocysteinemia. Recent studies have shown that these polymorphisms are also closely associated with different cancer types (Table 2). For instance, MTHFR has $\sim 6375$ polymorphisms, consisting of 650 deletions, 05 multiple base substitutions, 140 repeat variations, and $5580 \mathrm{SNPs}^{74}$. Two common polymorphisms, a $677 \mathrm{C}->\mathrm{T}$ transition at codon 222 (Ala222Val) ${ }^{19,27,63,73,75}$ and a 1298A- $>$ C transversion at codon 429 (Glu429Ala) ${ }^{75,76}$, have been reported to be associated with various cancer types, including endometrial carcinoma, esophageal squamous cell carcinoma (SCC), colon cancer, acute lymphocytic leukemia (ALL), and prostate cancer. In addition to $677 \mathrm{C}->\mathrm{T}$ and 1298A$>\mathrm{C}$, there is a third polymorphism, 1793G- $>\mathrm{A}$, whose frequency is very low ( $\sim 4.6 \%$ or less) and which is confined to colorectal cancer ${ }^{77}$. The $677 \mathrm{C}->\mathrm{T}$ polymorphism affects the protein's catalytic activity and the 1298A- $>$ C polymorphism affects its regulatory function ${ }^{20,78}$. Homozygotes $(677 \mathrm{CC}, \sim 60 \%)$ are more frequent than heterozygotes (677 CT, 31\%), but this pattern is reversed in the case of 1298 (1298AC, 53\% and 1298AA, 31\%). The $677 \mathrm{TT}$ and 1298CC homozygotes were found to have reduced prostate cancer risk, as the frequencies are very low (9 and $11 \%$, respectively) ${ }^{21,79}$. The risk factor associated with the $677 \mathrm{C}->\mathrm{T}$ polymorphism has been found to depend on the type of cancer, as it confers a higher risk for endometrial carcinoma ${ }^{80}(7)$, esophageal $\mathrm{SCC}^{81}$, and prostate cancer ${ }^{82-84}$, while it has little or no effect on the risk for colon cancer ${ }^{14,85,86}$ and acute lymphoid leuke$\mathrm{mia}^{87}$. The variable behavior of $677 \mathrm{C}->\mathrm{T}$ in different cancer types indicates that the environment or genetic background might help to dictate the activity of the polymorphism. In this context ${ }^{88}$, a number of factors have been proposed, including folate status, methionine, and the effects of alcohol consumption, to be the risk factor connecting the $677 \mathrm{C}->\mathrm{T}$ polymorphism to colorectal cancer. Another possibility is that the $677 \mathrm{C}->\mathrm{T}$ polymorphism is dominant negative in some cancer types but not in others based on the functional effect of the polymorphism.

MTRR has $\sim 9461$ polymorphisms, out of which 1051 are deletions, 01 are multiple base substitutions, 315 are repeat variations, and 8094 are SNPs ${ }^{89}$. Out of this pool, only one polymorphism (MTRR A66G, Ile22Met) ${ }^{14,18,90,91}$ has been studied and found to be associated with leukemia and colorectal cancer. This leukemic polymorphism has an allelic frequency of $51 \%$ in white populations ${ }^{87,90}$ Comparison of the relationships between homozygosity and heterozygosity and colorectal cancer revealed that homozygotes (GG) have a three-fold higher risk compared with that of heterozygotes $(A G)^{14,92}$. Since the leukemic allelic frequency is very high in the white population, it is important to investigate other populations to determine if genetic background affects the frequencies or functions of polymorphic MTRR.

Similarly, MTR has $\sim 26150$ polymorphisms, out of which 2643 are deletions, 06 are multiple base substitutions, 221 are repeat variations, and 23245 are SNPs ${ }^{105}$. One significant polymorphism (MTR A2756G; Asp919Gly) has been documented in MTR. This 2756A$>\mathrm{G}$ variant is associated with head, esophageal and neck squamous cell carcinoma, colorectal adenoma, colorectal carcinoma, lung cancer, multiple myeloma, cervical cancer, uterine cancer, and glioblastoma multiforme ${ }^{18,24,37,93-97}$. This polymorphism is associated with a decreased risk for colorectal cancer ${ }^{14,90}$, and no correlation could be established between this MTR variant and the incidence of breast and upper gastrointestinal tract carcinomas $^{98,99}$, suggesting that the severity of the effect of the polymorphism might depend on the type of cancer.

MTHFD-1 has $~ 16991$ polymorphisms, out of which 1913 are deletions, 07 are multiple base substitutions, 215 are repeat variations, and 14856 are $\mathrm{SNPs}^{100}$. One polymorphism (1958G->A; Ala653Gly) $)^{97,101,102}$ associated with acute lymphoid leukemia, which is located within the 10-formyl THF synthetase domain, has been reported ${ }^{103}$. No links between MTHFD variants and lung cancer risk could be established (Liu, Jin et al. 2008). Another polymorphism, (401G->A; Arg134Lys), which is in the cyclohydrolase/dehydrogenase domain, was also reported by ${ }^{102}$, but it is associated with a low colon cancer risk.

TYMS expression is a highly regulated process that is modulated by unique tandem repeat sequences and significant polymorphisms in the 5-UTR of the thymidylate synthase enhancer region (TSER) and in the 3-UTR 
(TS1494del6b) of the gene ${ }^{104}$. TYMS has $\sim 5892$ polymorphisms, out of which 1078 are deletions, 05 are multiple base substitutions, 398 are repeat variations, and 4411 are $\mathrm{SNPs}^{105}$. The TSER variant is most commonly present as double- $(2 \mathrm{R})$ and triple- (3R) repeat sequences, although $4 R, 5 R$, and $9 R$ repeats also exist. $3 R$ sequences show higher translational efficiency than $2 \mathrm{R}$ sequences. Homozygous 3R/3R subjects show higher TYMS protein expression and higher enzyme activity ${ }^{106}$. The second TYMS polymorphism identified is a $6 \mathrm{bp}$ deletion/insertion at bp 1494 in the 3-UTR of the TYMS gene. Several lines of evidence suggest that variation in the TYMS gene is associated with cancer risk. However, the risk factor associated with these polymorphisms depends on the type of cancer. In the cases of stomach, colorectal, and lung cancer, the TYMS enzyme activity and mRNA expression were found to be increased.

Transcobalamin II (TCN II) is a serum protein that transports vitamin B12 (cobalamin) from the ileum to other tissues. Vitamin B12 serves as an important molecule in the remethylation of methionine from Hcy and is important for the transformation of MTHF to THF. TCN-2 has $\sim 8291$ polymorphisms, out of which 1183 are deletions, 02 are multiple base substitutions, 146 are repeat variations, and 6960 are $\mathrm{SNPs}^{107}$. One common polymorphism in the TCN 2 gene is a $\mathrm{G}$ to $\mathrm{C}$ substitution $(776 \mathrm{G}>\mathrm{C}$, rs1801198) that results in replacement of a proline with an arginine ${ }^{108}$ In a recent meta-analysis, it was shown that subjects with the rs1801198 GG genotype had significantly lower concentrations of holotranscobalamin and higher Hcy levels compared to subjects with the rs1801198 CC genotype. This polymorphism has also been shown to be associated with different cancers, including colorectal cancer, ovarian cancer, glioblastoma, among others. However, most of the cancer types did not have close association, as indicated by OR values near or equal to 1 . Colorectal cancer, ovarian cancer, and central nervous system lymphoma, on the other hand, have higher OR values and, therefore, exhibit significant association (Table 2). Therefore, it is thought that the TCN 2 polymorphism rs1801198 significantly alters the circulating holotranscobalamin levels. Since TCN 2 plays a vital role in vitamin B12 metabolism, it is reasonable to suspect that the rs 1801198 polymorphism may affect pathological conditions related to vitamin B12 deficiency.

$B H M T$ has $\sim 5271$ polymorphisms, out of which 484 are deletions, 01 multiple base substitution, 140 are repeat variations, and 4648 are $\mathrm{SNPs}^{109}$. Out of these variations, three significant mutations (Gly199Ser, Glu239Arg, and Glu406His) and one polymorphism have been examined. The polymorphism is the $\mathrm{G}$ to A substitution $(742 \mathrm{G}>\mathrm{A}$, rs3733890), which replaces arginine by glutamine at codon
239. A study incorporating meta-analysis was performed to investigate the rs3733890 polymorphism and cancer susceptibility. It was shown that this polymorphism showed no statistically significant association with increased risk of various cancers, including head and squamous cell carcinoma, breast cancer, ovarian cancer, colorectal adenoma, and liver cancer. However, a negative association was observed in uterine cervical cancer (Table 2).

CBS has $\sim 6617$ polymorphisms, out of which 573 are deletions, 04 are multiple base substitutions, 1059 are repeat variations, and 4981 are $\mathrm{SNPs}^{110}$. Interestingly, none of these mutations have been shown to cause any significant predisposition towards any type of cancer ${ }^{111}$. This observation opens an avenue for future research studies focusing on understanding and identifying the frequencies of BHMT and $C B S$ genotypes and their associations with and prevalence in different cancer types.

\section{I (f) CBS is associated with cancer via $\mathrm{H}_{2} \mathrm{~S}$ production}

$\mathrm{H}_{2} \mathrm{~S}$, which is a signaling molecule, is substantially involved in vasorelaxation, acting as a neuromodulator ${ }^{112,113}$. Recently, $\mathrm{H}_{2} \mathrm{~S}$ has gained attention in cancer due to its cytotoxic and cytoprotective effects. It plays a key role in the bioenergetics of tumor cells and stimulates their proliferation, migration, and invasion ${ }^{114-116}$. In humans, CBS normally catalyzes the condensation of serine with homocysteine to produce cystathionine and water, a pivotal reaction in the trans-sulfuration pathway. In an alternative reaction, $C B S$ can produce $\mathrm{H}_{2} \mathrm{~S}$ via $\beta$-elimination and $\beta$-replacement ${ }^{117}$ reactions. The $\beta$-elimination reaction involves catalysis of cysteine by $\mathrm{CBS}$ with corresponding $\mathrm{H}_{2} \mathrm{~S}$ production, whereas in the $\beta$-replacement mechanism, the reaction between L-cysteine and 2-mercaptoethanol enables CBS to produce $\mathrm{H}_{2} \mathrm{~S}$. Various clinical studies have shown that there is $C B S$ overexpression and, hence, increased $\mathrm{H}_{2} \mathrm{~S}$ production, in many cancer types, including colon, ovarian, gastric, colorectal, prostate, gastroesophageal cancer, and endometrial cell angiogenesis ${ }^{118-121}$ (Fiorucci, Antonelli et al.; ${ }^{118}$ Guo, Gai et al.; ${ }^{119}$ Bhattacharyya, Saha et al.; ${ }^{120}$ Szabo, Coletta et al. 2013; Modis, Coletta et al. 2014; Hellmich, Coletta et al.; ${ }^{122}$ Katsouda, Bibli et $\mathrm{al}^{121}$.). The role of $\mathrm{H}_{2} \mathrm{~S}$ in cancer has been elucidated. It is known to enhance tumor growth and increase cellular proliferation by (i) stimulating cellular bioenergetics, (ii) activating proliferative, migratory, and invasive signaling pathways, and (iii) enhancing angiogenesis in tumors ${ }^{122}$. Other studies have demonstrated that HCT116 cells (a transformed cell line) have CBS upregulation and enhanced $\mathrm{H}_{2} \mathrm{~S}$ production compared to nontransformed cells ${ }^{123}$.

ShRNA-mediated silencing of $C B S$ or suppression of its activity by pharmacological means (using aminooxyacetic acid) ${ }^{124}$ results in reduced mitochondrial function (ATP 
turnover, respiratory reserve capacity, and oxygen consumption) and impaired glycolysis ${ }^{112}$. A clinical study of colon cancer showed reduced angiogenesis and increased growth in xenografts derived from colon cancer patients incubated in mice treated with aminooxyacetic acid ${ }^{125}$. Alternatively, $\mathrm{H}_{2} \mathrm{~S}$ production induces angiogenesis in various experimental models ${ }^{114}$. In another development ${ }^{126}$, investigated the effects of S-adenosyl-Lmethionine (SAM) on tumor bioenergetics ${ }^{127,128}$. SAM is an allosteric activator of CBS that binds to the regulatory domain of $C B S$. The study revealed that SAM enhances $\mathrm{H}_{2} \mathrm{~S}$ production of in the HCT116 cancer cell line. Mechanistically, it is not completely known how $\mathrm{H}_{2} \mathrm{~S}$ helps to stimulate tumor growth ${ }^{129}$. However, it has been argued that $\mathrm{H}_{2} \mathrm{~S}$ serves as an autocrine stimulator during tumor proliferation. Therefore, modulation of the CBS and $\mathrm{H}_{2} \mathrm{~S}$ levels could help limit cancer proliferation and promote its reversal.

\section{Conclusion}

It is clear from this review that there are compelling genetic, epigenetic and environmental factors that establish a close association between disturbed Hcy metabolism and cancer. Therefore, Hcy-elevating drugs should be restrictively prescribed to cancer patients, and clinicians should closely monitor Hcy levels after chemotherapy or surgery. To date, the effects of Hcy on the growth and proliferation of tumor cells remain poorly understood. Insight into the effects of Hcy on the growth and proliferation of cancer cells would yield novel, promising strategies to curb cancer. Nevertheless, Hcy can be used as a potential tumor biomarker for a variety of cancers.

\section{Conflict of interest}

The authors declare that they have no conflict.

\section{Publisher's note}

Springer Nature remains neutral with regard to jurisdictional claims in published maps and institutional affiliations.

Received: 24 May 2018 Revised: 14 November 2018 Accepted: 16 November 2018.

Published online: 21 February 2019

\section{References}

1. Mcdonald, L., Bary, C., Field, C., Love, F. \& Davies, B. Homocystinuria, thrombosis, and the blood-platelets. Lancet 1, 745-746 (1964).

2. Sharma, G. S., Kumar, T., Dar, T. A. \& Singh, L. R. Protein N-homocysteinylation: from cellular toxicity to neurodegeneration. Biochim. Biophys. Acta $\mathbf{1 8 5 0}$ 2239-2245 (2015).

3. Morganti, M. et al. Atherosclerosis and cancer: common pathways on the vascular endothelium. Biomed. Pharmacother. 56, 317-324 (2002).

4. Brustolin, S., Giugliani, R. \& Félix, T. M. Genetics of homocysteine metabolism and associated disorders. Braz. J. Med. Biol. Res. 43, 1-7 (2010).

5. Stolzenberg-Solomon, R. Z. et al. Pancreatic cancer risk and nutrition-related methyl-group availability indicators in male smokers. J. Natl. Cancer Inst. 91, 535-541 (1999).
6. Seshadri, S. et al. Plasma homocysteine as a risk factor for dementia and Alzheimer's disease. N. Engl. J. Med. 346, 476-483 (2002).

7. Vafai, S. B. \& Stock, J. B. Protein phosphatase 2 A methylation: a link between elevated plasma homocysteine and Alzheimer's Disease. FEBS Lett. 518, 1-4 (2002).

8. Ruud, E., Holmstrøm, H., Brosstad, F. \& Wesenberg, F. Children with acute lymphoblastic leukaemia have high plasma levels of total homocysteine at time of diagnosis. Scand. J. Clin. Lab. Invest. 66, 67-78 (2006).

9. Ho, R. C. M. et al. Is high homocysteine level a risk factor for cognitive decline in elderly? a systematic review, meta-analysis, and meta-regression. Am. J. Geriatr. Psychiatry 19, 607-617 (2011).

10. Mattson, M. P. \& Shea, T. B. Folate and homocysteine metabolism in neural plasticity and neurodegenerative disorders. Trends Neurosci. 26, 137-146 (2003).

11. Obeid, R. \& Herrmann, W. Mechanisms of homocysteine neurotoxicity in neurodegenerative diseases with special reference to dementia. FEBS Lett. 580, 2994-3005 (2006).

12. Seshadri, S. Elevated plasma homocysteine levels: risk factor or risk marker for the development of dementia and Alzheimer's disease? J. Alzheimers Dis. $\mathbf{9}$, 393-398 (2006).

13. Giovannucci, E. et al. Alcohol, low-methionine--low-folate diets, and risk of colon cancer in men. J. Natl. Cancer Inst. 87, 265-273 (1995).

14. $\mathrm{Ma}$, J. et al. A polymorphism of the methionine synthase gene: association with plasma folate, vitamin B12, homocyst(e)ine, and colorectal cancer risk. Cancer Epidemiol. Biomark. Prev. 8, 825-829 (1999).

15. Bravatà, V. Controversial roles of methylenetetrahydrofolate reductase polymorphisms and folate in breast cancer disease. Int. J. Food Sci. Nutr. 66, 43-49 (2015).

16. Kato, I. et al. Serum folate, homocysteine and colorectal cancer risk in women: a nested case-control study. Br. J. Cancer 79, 1917-1921 (1999).

17. de Jong, M. M. et al. Low-penetrance genes and their involvement in colorectal cancer susceptibility. Cancer Epidemiol. Biomark. Prev. 11, 1332-1352 (2002).

18. Matsuo, K. et al. Methionine synthase reductase gene A66G polymorphism is associated with risk of colorectal cancer. Asian Pac. J. Cancer Prev. 3, 353-359 (2002).

19. Robien, K. \& Ulrich, C. M. 5,10-Methylenetetrahydrofolate reductase polymorphisms and leukemia risk: a HuGE minireview. Am. J. Epidemiol. 157, 571-582 (2003).

20. Krajinovic, M. et al. Role of MTHFR genetic polymorphisms in the susceptibility to childhood acute lymphoblastic leukemia. Blood 103, 252-257 (2004).

21. Singal, R., Ferdinand, L., Das, P. M., Reis, I. M. \& Schlesselman, J. J. Polymorphisms in the methylenetetrahydrofolate reductase gene and prostate cancer risk. Int. J. Oncol. 25, 1465-1471 (2004).

22. Matsuo, K. et al. One-carbon metabolism related gene polymorphisms interact with alcohol drinking to influence the risk of colorectal cancer in Japan. Carcinogenesis 26, 2164-2171 (2005).

23. Mancardi, D. et al. Physiological and pharmacological features of the novel gasotransmitter: hydrogen sulfide. Biochim. Biophys. Acta 1787, 864-872 (2009).

24. $\mathrm{Wu}, \mathrm{L} . \mathrm{L}$. \& $\mathrm{Wu}$, J. T. Hyperhomocysteinemia is a risk factor for cancer and a new potential tumor marker. Clin. Chim. Acta 322, 21-28 (2002).

25. Scott, J. M. \& Weir, D. G. Folic acid, homocysteine and one-carbon metabolism: a review of the essential biochemistry. J. Cardiovasc. Risk 5, 223-227 (1998).

26. Selhub, J. Homocysteine metabolism. Annu. Rev. Nutr. 19, 217-246 (1999).

27. Jacques, P. F. et al. Relation between folate status, a common mutation in methylenetetrahydrofolate reductase, and plasma homocysteine concentrations. Circulation 93, 7-9 (1996).

28. Schwahn, B. C. et al. Homocysteine-betaine interactions in a murine model of 5,10-methylenetetrahydrofolate reductase deficiency. FASEB J. 17, 512-514 (2003).

29. Williams, K. T. \& Schalinske, K. L. New insights into the regulation of methyl group and homocysteine metabolism. J. Nutr. 137, 311-314 (2007).

30. Locasale, J. W. Serine, glycine and one-carbon units: cancer metabolism in full circle. Nat. Rev. Cancer 13, 572-583 (2013).

31. Zhang, S. M. et al. Plasma folate, vitamin B6, vitamin B12, homocysteine, and risk of breast cancer. J. Natl. Cancer Inst. 95, 373-380 (2003).

32. Siniscalchi, A. et al. Increase in plasma homocysteine levels induced by drug treatments in neurologic patients. Pharmacol. Res. 52, 367-375 (2005). 
33. Smith, J. L., Goldsmith, G. A. \& Lawrence, J. D. Effects of oral contraceptive steroids on vitamin and lipid levels in serum. Am. J. Clin. Nutr. 28, 371-376 (1975).

34. Grant, E. C. G. The contraceptive pill: its relation to allergy and illness. Nutr. Health 2, 33-40 (1983).

35. Amatayakul, K., Uttaravichai, C., Singkamani, R. \& Ruckphaopunt, S. Vitamin metabolism and the effects of multivitamin supplementation in oral contraceptive users. Contraception 30, 179-196 (1984).

36. Hjelt, K., Brynskov, J., Hippe, E., Lundström, P. \& Munck, O. Oral contraceptives and the cobalamin (Vitamin B ${ }_{12}$ ) metabolism. Acta Obstet. Gynecol. Scand. 64, 59-63 (1985).

37. Obwegeser, R., Hohlagschwandtner, M. \& Sinzinger, H. Homocysteine-a pathophysiological cornerstone in obstetrical and gynaecological disorders? Hum. Reprod. Update 5, 64-72 (1999).

38. Montfort, W. R. et al. Structure, multiple site binding, and segmenta accommodation in thymidylate synthase on binding dUMP and an antifolate. Biochemistry 29, 6964-6977 (1990).

39. Blount, B. C. et al. Folate deficiency causes uracil misincorporation into human DNA and chromosome breakage: implications for cancer and neuronal damage. Proc. Natl Acad. Sci. USA 94, 3290-3295 (1997).

40. Hay, R. K. M., Park, J.-G. \& Gazdar, A. Atlas of Human Tumor Cell Lines. (Elsevier Science, Amsterdam, 1994).

41. Crider, K. S., Yang, T. P., Berry, R. J. \& Bailey, L. B. Folate and DNA methylation: a review of molecular mechanisms and the evidence for Folate's role. Adv. Nutr. 3, 21-38 (2012)

42. Hall, L. E, Mitchell, S. E. \& O'Neill, R. J. Pericentric and centromeric transcription: a perfect balance required. Chromosom. Res. 20, 535-546 (2012).

43. Ehrlich, M. DNA hypomethylation, cancer, the immunodeficiency, centromeric region instability, facial anomalies syndrome and chromosomal rearrangements. J. Nutr. 132, 2424S-2429S (2002)

44. Ehrlich, M. DNA methylation in cancer: too much, but also too little. Oncogene 21, 5400-5413 (2002).

45. Zhang, D., Wen, X., Wu, W., Guo, Y. \& Cui, W. Elevated homocysteine level and folate deficiency associated with increased overall risk of carcinogenesis: meta-analysis of 83 case-control studies involving 35,758 individuals. PLoS ONE 10, e0123423 (2015).

46. Stathopoulou, A. et al. Molecular detection of cytokeratin-19-positive cells in the peripheral blood of patients with operable breast cancer: evaluation of their prognostic significance. J. Clin. Oncol. 20, 3404-3412 (2002).

47. Refsum, H. et al. The Hordaland Homocysteine Study: a community-based study of homocysteine, its determinants, and associations with disease. $J$. Nutr. 136, 1731S-1740S (2006).

48. Sun, C.-F., Haven, T. R., Wu, T.-L., Tsao, K.-C. \& Wu, J. T. Serum total homocysteine increases with the rapid proliferation rate of tumor cells and decline upon cell death: a potential new tumor marker. Clin. Chim. Acta 321, 55-62 (2002)

49. Akoglu, B., Milovic, V., Caspary, W. F. \& Faust, D. Hyperproliferation of homocysteinetreated colon cancer cells is reversed by folate and 5methyltetrahydrofolate. Eur. J. Nutr. 43, 93-99 (2004).

50. Rickles, F. R., Levine, M. \& Edwards, R. L. Hemostatic alterations in cancer patients. Cancer Metastas-. Rev. 11, 237-248 (1992).

51. GATT, A. et al. Hyperhomocysteinemia in women with advanced breast cancer. Int. J. Lab. Hematol. 29, 421-425 (2007)

52. Green, K. B. \& Silverstein, R. L. Hypercoagulability in cancer. Hematol. Oncol. Clin. North Am. 10, 499-530 (1996).

53. Heit, J. A. et al. Relative impact of risk factors for deep vein thrombosis and pulmonary embolism: a population-based study. Arch. Intern. Med. 162 1245-1248 (2002).

54. Kakkar, A., Haas, S., Walsh, D. \& Encke, A. Prevention of perioperative venous thromboembolism: outcome after cancer and noncancer surgery. Br. J. Surg. 88, 47 (2001).

55. Zhu, $\mathrm{H}$. et al. Homocysteine remethylation enzyme polymorphisms and increased risks for neural tube defects. Mol. Genet. Metab. 78, 216-221 (2003).

56. Welch, G. N. \& Loscalzo, J. Homocysteine and atherothrombosis. N. Engl. J. Med. 338, 1042-1050 (1998).

57. Chowhan, R. K., Mittal, S., Dar, T. A., Kamal, M. A. \& Singh, L. R. lgnored avenues in alpha-synuclein associated proteopathy. CNS Neurol. Disord. Drug Targets 13, 1246-1257 (2014)

58. Sharma, G. S., Kumar, T. \& Singh, L. R. N-homocysteinylation induces different structural and functional consequences on acidic and basic proteins. PLOS ONE 9, e116386 (2014).
59. Kumar, T., Sharma, G. S. \& Singh, L. R. Homocystinuria: therapeutic approach. Clin. Chim. Acta 458, 55-62 (2016).

60. Lentz, S. R. et al. Vascular dysfunction in monkeys with diet-induced hyperhomocyst (e) inemia. J. Clin. Invest. 98, 24-29 (1996).

61. Chandrasekharan, N. V. et al. COX-3, a cyclooxygenase-1 variant inhibited by acetaminophen and other analgesic/antipyretic drugs: Cloning, structure, and expression. Proc. Natl Acad. Sci. USA 99, 13926-13931 (2002).

62. FitzGerald, G. A. Parsing an enigma: the pharmacodynamics of aspirin resistance. Lancet 361, 542-544 (2003).

63. Goyette, P. et al. Human methylenetetrahydrofolate reductase: isolation of CDNA, mapping and mutation identification. Nat. Genet. 7, 195-200 (1994).

64. Goyette, P., Frosst, P., Rosenblatt, D. S. \& Rozen, R. Seven novel mutations in the methylenetetrahydrofolate reductase gene and genotype/phenotype correlations in severe methylenetetrahydrofolate reductase deficiency. Am. J. Hum. Genet 56, 1052-1059 (1995).

65. Kluijtmans, L. A. et al. Identification of four novel mutations in severe methylenetetrahydrofolate reductase deficiency. Eur. J. Hum. Genet. 6, 257-265 (1998).

66. Weisberg, I., Tran, P., Christensen, B., Sibani, S. \& Rozen, R. A second genetic polymorphism in methylenetetrahydrofolate reductase (MTHFR) associated with decreased enzyme activity. Mol. Genet. Metab. 64, 169-172 (1998).

67. Sibani, S. et al. Characterization of six novel mutations in the methylenetetrahydrofolate reductase (MTHFR) gene in patients with homocystinuria. Hum. Mutat. 15, 280-287 (2000).

68. Tonetti, C., Amiel, J., Munnich, A. \& Zittoun, J. Impact of new mutations in the methylenetetrahydrofolate reductase gene assessed on biochemical phenotypes: a familial study. J. Inherit. Metab. Dis. 24, 833-842 (2001).

69. Sharp, L. \& Little, J. Polymorphisms in genes involved in folate metabolism and colorectal neoplasia: a HuGE review. Am. J. Epidemiol. 159, 423-443 (2004).

70. Yano, $\mathrm{H}$. et al. Mutations of the MTHFR gene (428C $>\mathrm{T}$ and $[458 \mathrm{G}>\mathrm{T}+$ 459C > T]) markedly decrease MTHFR enzyme activity. Neurogenetics $\mathbf{5}$ 135-140 (2004).

71. van der Put, N. M. et al. Mutated methylenetetrahydrofolate reductase as a risk factor for spina bifida. Lancet 346, 1070-1071 (1995).

72. Kluijtmans, L. A. et al. Molecular genetic analysis in mild hyperhomocysteinemia: a common mutation in the methylenetetrahydrofolate reductase gene is a genetic risk factor for cardiovascular disease. Am. J. Hum. Genet. 58, 35-41 (1996).

73. Brezovska-Kavrakova, J. et al. Hyperhomocysteinemia and of methylenetetrahydrofolate reductase (C677T) genetic polymorphism in patients with deep vein thrombosis. Mater. Sociomed. 25, 170-174 (2013).

74. mthfr - SNP - NCBI. Available at: https:/www.ncbi.nlm.nih.gov/snp/? term $=$ mthfr. Accessed 14 November 2018

75. Frosst, P. et al. A candidate genetic risk factor for vascular disease: a common mutation in methylenetetrahydrofolate reductase. Nat. Genet. 10, 111-113 (1995).

76. Weisberg, I. S. et al. The 1298A-->C polymorphism in methylenetetrahydrofolate reductase (MTHFR): in vitro expression and association with homocysteine. Atherosclerosis 156, 409-415 (2001).

77. Etienne-Grimaldi, M.-C. et al. Methylenetetrahydrofolate reductase (MTHFR) gene polymorphisms and FOLFOX response in colorectal cancer patients. $\mathrm{Br}$. J. Clin. Pharmacol. 69, 58-66 (2010).

78. Ma, J. et al. Methylenetetrahydrofolate reductase polymorphism, dietary interactions, and risk of colorectal cancer. Cancer Res. 57, 1098-1102 (1997).

79. Safarinejad, M. R., Shafiei, N. \& Safarinejad, S. Relationship between three polymorphisms of methylenetetrahydrofolate reductase (MTHFR C677T, A1298C, and G1793A) gene and risk of prostate cancer: a case-control study. Prostate 70, 1645-1657 (2010).

80. Esteller, M.t Garcia, A., Martinez-Palones, J. M., Xercavins, J. \& Reventos, J. Germ line polymorphisms in cytochrome-P450 1A1 (C4887 CYP1A1) and methylenetetrahydrofolate reductase (MTHFR) genes and endometrial cancer susceptibility. Carcinogenesis 18, 2307-2311 (1997).

81. Song, C., Xing, D., Tan, W., Wei, Q. \& Lin, D. Methylenetetrahydrofolate reductase polymorphisms increase risk of esophageal squamous cell carcinoma in a Chinese population. Cancer Res. 61, 3272-3275 (2001).

82. Van Guelpen, B. R. et al. Polymorphisms of methylenetetrahydrofolate reductase and the risk of prostate cancer: a nested case-control study. Eur. J. Cancer Prev. 15, 46-50 (2006).

83. Johansson, $\mathrm{M}$. et al. Circulating concentrations of folate and vitamin B12 in relation to prostate cancer risk: results from the European Prospective 
Investigation into Cancer and Nutrition Study. Cancer Epidemiol. Biomark. Prev. 17, 279-285 (2008).

84. Shannon, J. et al. Folate intake and prostate cancer risk: a case-control study Nutr. Cancer 61, 617-628 (2009)

85. Marugame, T. et al. Methylenetetrahydrofolate reductase polymorphism and risk of colorectal adenomas. Cancer Lett. 151, 181-186 (2000).

86. Ulrich, C. M., Robien, K. \& Sparks, R. Pharmacogenetics and folate metabolism -a promising direction. Pharmacogenomics 3, 299-313 (2002).

87. Skibola, C. F. et al. Polymorphisms in the methylenetetrahydrofolate reductase gene are associated with susceptibility to acute leukemia in adults. Proc. Natl Acad. Sci. USA 96, 12810-12815 (1999).

88. Curtin, K. et al. Genetic polymorphisms in one-carbon metabolism: associations with $\mathrm{CpG}$ island methylator phenotype (CIMP) in colon cancer and the modifying effects of diet. Carcinogenesis 28, 1672-1679 (2007).

89. mtrr - SNP - NCBI. Available at: https://www.ncbi.nlm.nih.gov/snp/? term=mtrr. Accessed 14 November 2018.

90. Wilson, A. et al. A common variant in methionine synthase reductase combined with low cobalamin $\left(V_{i t a m i n} B_{12}\right)$ increases risk for spina bifida. Mol. Genet. Metab. 67, 317-323 (1999).

91. Jacques, P. F. et al. Effects of polymorphisms of methionine synthase and methionine synthase reductase on total plasma homocysteine in the NHLB Family Heart Study. Atherosclerosis 166, 49-55 (2003).

92. Goelz, S. E., Vogelstein, B., Hamilton, S. R. \& Feinberg, A. P. Hypomethylation of DNA from benign and malignant human colon neoplasms. Science $\mathbf{2 2 8}$ 187-190 (1985).

93. Alberg, A. J. et al. The risk of cervical cancer in relation to serum concentrations of folate, vitamin B12, and homocysteine. Cancer Epidemiol. Biomark. Prev. 9, 761-764 (2000).

94. Powers, H. J. Interaction among folate, riboflavin, genotype, and cancer, with reference to colorectal and cervical cancer. J. Nutr. 135, 2960S-2966S (2005).

95. Mostowska, A., Hozyasz, K. \& Jagodzinski, P. Maternal MTR genotype contributes to the risk of non-syndromic cleft lip and palate in the Polish population. Clin. Genet. 69, 512-517 (2006).

96. Stolzenberg-Solomon, R. Z. et al. Folate intake, alcohol use, and postmenopausal breast cancer risk in the prostate, lung, colorectal, and ovarian cancer screening trial. Am. J. Clin. Nutr. 83, 895-904 (2006).

97. Charasson, V. et al. Involvement of gene polymorphisms of the folate pathway enzymes in gene expression and anticancer drug sensitivity using the NCI-60 panel as a model. Eur. J. Cancer 45, 2391-2401 (2009).

98. Ott, N., Geddert, H. \& Sarbia, M. Polymorphisms in methionine synthase (A2756G) and cystathionine-synthase (844ins68) and susceptibility to carcinomas of the upper gastrointestinal tract. J. Cancer Res Clin. Oncol. 134, 405-410 (2008).

99. Hua Tao, M. et al. Null results in brief DNA promoter methylation in breast tumors: no association with genetic polymorphisms in MTHFR and MTR. Cancer Epidemiol. Biomark. Prev. 18, 998-1002 (2009).

100. mthfd - SNP - NCBI. Available at: https:/www.ncbinlm.nih.gov/snp/? term=mthfd. Accessed 14 November 2018

101. Parle-McDermott, A. et al. MTHFD1 R653Q polymorphism is a maternal genetic risk factor for severe abruptio placentae. Am. J. Med. Genet. Part A 132A, 365-368 (2005).

102. Wang, L. et al. Polymorphisms of MTHFD, plasma homocysteine levels, and risk of gastric cancer in a high-risk Chinese population. Clin. Cancer Res. 13, 2526-2532 (2007).

103. Hol, F. A. et al. Molecular genetic analysis of the gene encoding the trifunctional enzyme MTHFD (methylenetetrahydrofolate-dehydrogenase, methenyltetrahydrofolate-cyclohydrolase, formyltetrahydrofolate synthetase) in patients with neural tube defects. Clin. Genet. 53, 119-125 (2008).

104. Sulzyc-Bielicka, V. et al. Thymidylate synthase gene polymorphism and survival of colorectal cancer patients receiving adjuvant 5-fluorouracil. Genet. Test. Mol. Biomark. 17, 799-806 (2013).

105. tyms - SNP - NCBI. Available at: https:/www.ncbi.nlm.nih.gov/snp/? term=tyms. Accessed 14 November 2018.

106. Kawakami, K, . \& Omura, K. \& Kanehira, E. \& Watanabe, Y. Polymorphic tandem repeats in the thymidylate synthase gene is associated with its protein expression in human gastrointestinal cancers.Anticancer. Res. 19, 3249-3252 (1999).

107. tcn II - SNP - NCBI. Available at: https://www.ncbi.nlm.nih.gov/snp/?term=tcn +Il. Accessed 14 November 2018.

108. Oussalah, A., Levy, J., Filhine-Trésarrieu, P., Namour, F. \& Guéant, J.-L. Association of TCN2 rs1801198 c.776G--> C polymorphism with markers of one- carbon metabolism and related diseases: a systematic review and metaanalysis of genetic association studies. Am. J. Clin. Nutr. 106, 1142-1156 (2017).

109. bhmt - SNP - NCBI. Available at: https:/www.ncbi.nlm.nih.gov/snp/? term=bhmt. Accessed 14 November 2018.

110. cbs - SNP - NCBI. Available at: https://www.ncbi.nlm.nih.gov/snp/?term=cbs. Accessed 14 November 2018

111. $\mathrm{Xu}, \mathrm{X}$. et al. Choline metabolism and risk of breast cancer in a populationbased study. FASEB J. 22, 2045-2052 (2008).

112. Majtan, T., Singh, L. R., Wang, L., Kruger, W. D. \& Kraus, J. P. Active cystathionine $\beta$-synthase can be expressed in heme-free systems in the presence of metal-substituted porphyrins or a chemical chaperone. J. Biol. Chem. $\mathbf{2 8 3}$ 34588-34595 (2008).

113. Szabo, C. et al. Regulation of mitochondrial bioenergetic function by hydrogen sulfide. Part I. Biochemical and physiological mechanisms. Br. J. Pharmacol. 171, 2099-2122 (2014).

114. Szabó, C. Hydrogen sulphide and its therapeutic potential. Nat. Rev. Drug Discov. 6, 917-935 (2007)

115. Szabó, C. \& Papapetropoulos, A. Hydrogen sulphide and angiogenesis: mechanisms and applications. Br. J. Pharmacol. 164, 853-865 (2011).

116. Whiteman, M., Le Trionnaire, S., Chopra, M., Fox, B. \& Whatmore, J. Emerging role of hydrogen sulfide in health and disease: critical appraisal of biomarkers and pharmacological tools. Clin. Sci. 121, 459-488 (2011).

117. Kimura, H. Hydrogen sulfide as a neuromodulator. Mol. Neurobiol. 26 013-020 (2002).

118. Fiorucci, S. et al. Inhibition of hydrogen sulfide generation contributes to gastric injury caused by anti-inflammatory nonsteroidal drugs. Gastroenterology 129, 1210-1224 (2005).

119. Guo, H. et al. Characterization of hydrogen sulfide and its synthases, cystathionine $\beta$-Synthase and cystathionine $\gamma$-Lyase, in human prostatic tissue and cells. Urology 79, 483.e1-483.e5 (2012).

120. Bhattacharyya, S. et al. Cystathionine beta-synthase (cbs) contributes to advanced ovarian cancer progression and drug resistance. PLOS ONE 8 , e79167 (2013)

121. Katsouda, A., Bibli, S.-I., Pyriochou, A., Szabo, C. \& Papapetropoulos, A. Regulation and role of endogenously produced hydrogen sulfide in angiogenesis. Pharmacol. Res. 113, 175-185 (2016).

122. Hellmich, M. R. \& Szabo, C. Hydrogen sulfide and cancer. Handb. Exp. Pharmacol. 230, 233-241 (2015)

123. Módis, K. et al. Regulation of mitochondrial bioenergetic function by hydrogen sulfide. Part II. Pathophysiological and therapeutic aspects. Br. J. Pharmacol. 171, 2123-2146 (2014).

124. Singh, S., Padovani, D., Leslie, R. A., Chiku, T. \& Banerjee, R. Relative contributions of cystathionine $\beta$-Synthase and $\gamma$-Cystathionase to $\mathrm{H}_{2} \mathrm{~S}$ biogenesis via alternative trans-sulfuration reactions. J. Biol. Chem. 284, 22457-22466 (2009).

125. Winkler, L. R. et al. Population structure and genotype-phenotype associations in a collection of oat landraces and historic cultivars. Front. Plant Sci. 7, 1077 (2016)

126. Módis, K. et al. Effect of S-adenosyl---methionine (SAM), an allosteric activator of cystathionine- $\beta$-synthase (CBS) on colorectal cancer cell proliferation and bioenergetics in vitro. Nitric Oxide 41, 146-156 (2014).

127. Singh, L. R., Chen, X., Kožich, V. \& Kruger, W. D. Chemical chaperone rescue of mutant human cystathionine $\beta$-synthase. Mol. Genet. Metab. 91, 335-342 (2007).

128. Koutmos, M., Kabil, O., Smith, J. L. \& Banerjee, R. Structural basis for substrate activation and regulation by cystathionine beta-synthase (CBS) domains in cystathionine -synthase. Proc. Natl Acad. Sci. USA 107, 20958-20963 (2010).

129. Singh, L. R., Gupta, S., Honig, N. H., Kraus, J. P. \& Kruger, W. D. Activation of mutant enzyme function in vivo by proteasome inhibitors and treatments that induce Hsp70. PLoS Genet. 6, e1000807 (2010).

130. Mudd, S. H. et al. Homocysteine and its disulfide derivatives. Arterioscler. Thromb. Vasc. Biol. 20, 1704-1706 (2000).

131. Mudd, S. H. et al. The natural history of homocystinuria due to cystathionine beta-synthase deficiency. Am. J. Hum. Genet 37, 1-31 (1985).

132. Wilcken, D. E. \& Wilcken, B. The pathogenesis of coronary artery disease. A possible role for methionine metabolism. J. Clin. Invest. 57, 1079-1082 (1976).

133. Eberhardt, R. T. et al. Endothelial dysfunction in a murine model of mild hyperhomocyst (e) inemia. J. Clin. Invest. 106, 483-491 (2000). 
134. Harker, L. A., Harlan, J. M. \& Ross, R. Effect of sulfinpyrazone on homocysteineinduced endothelial injury and arteriosclerosis in baboons. Circ. Res. 53, 731-739 (1983).

135. Quadri, P. et al. Homocysteine, folate, and vitamin B-12 in mild cognitive impairment, Alzheimer disease, and vascular dementia. Am. J. Clin. Nutr. 80, 114-122 (2004).

136. Mcllroy, S. P., Dynan, K. B., Lawson, J. T., Patterson, C. C. \& Passmore, A. P. Moderately elevated plasma homocysteine, methylenetetrahydrofolate reductase genotype, and risk for stroke, vascular dementia, and Alzheimer disease in Northern Ireland. Stroke 33, 2351-2356 (2002).

137. Rosenquist, T. H., Ratashak, S. A. \& Selhub, J. Homocysteine induces congenital defects of the heart and neural tube: effect of folic acid. Proc. Natl Acad. Sci. USA 93, 15227-15232 (1996).

138. Hobbs, C. A., Cleves, M. A., Melnyk, S., Zhao, W. \& James, S. J. Congenital heart defects and abnormal maternal biomarkers of methionine and homocysteine metabolism. Am. J. Clin. Nutr. 81, 147-153 (2005).

139. McDowell, I. F. \& Lang, D. Homocysteine and endothelial dysfunction: a link with cardiovascular disease. J. Nutr. 130, 369S-372S (2000).

140. Refsum, H., Ueland, P. M., Nygard, O. \& Vollset, S. E. Homocysteine and cardiovascular disease. Annu Rev. Med 49, 31-62 (1998).

141. Martignoni, E. et al. Homocysteine and Parkinson's disease: a dangerous liaison? J. Neurol. Sci. 257, 31-37 (2007).

142. Lamberti, P. et al. Effects of levodopa and COMT inhibitors on plasma homocysteine in Parkinson's disease patients. Mov. Disord. 20, 69-72 (2005).

143. Moustafa, A. A., Hewedi, D. H., Eissa, A. M., Frydecka, D. \& Misiak, B. Homocysteine levels in schizophrenia and affective disorders-focus on cognition. Front. Behav. Neurosci. 8, 343 (2014).

144. Muntjewerff, J.-W., Kahn, R. S., Blom, H. J. \& den Heijer, M. Homocysteine, methylenetetrahydrofolate reductase and risk of schizophrenia: a metaanalysis. Mol. Psychiatry 11, 143 (2006).

145. Leblhuber, F. et al. Hyperhomocysteinemia in dementia. J. Neural Transm. 107, 1469-1474 (2000).

146. Shea, T. B. \& Rogers, E. Homocysteine and dementia. N Engl J Med 346, 2007-2008 (2002).

147. Tiemeier, $H$. et al. Vitamin $B_{12}$, folate, and homocysteine in depression: the Rotterdam Study. Am. J. Psychiatry 159, 2099-2101 (2002).

148. Almeida, O. P. et al. Homocysteine and depression in later life. Arch. Gen. Psychiatry 65, 1286-1294 (2008).

149. Janula, A. et al. Homocysteine and diabetes. Wiad. Lek. (Wars., Pol. 1960) 58, 319-323 (2005).

150. Baliga, B. S., Reynolds, T., Fink, L. M. \& Fonseca, V. A. Hyperhomocysteinemia in type 2 diabetes mellitus: cardiovascular risk factors and effect of treatment with folic acid and pyridoxine. Endocr. Pract. 6, 435-441 (2000).

151. Gueant, J. L. et al. Homocysteine and related genetic polymorphisms in Down's syndrome IQ. J. Neurol. Neurosurg. Psychiatry 76, 706-709 (2005).

152. Schuh, S. et al. Homocystinuria and megaloblastic anemia responsive to vitamin B12 therapy. An inborn error of metabolism due to a defect in cobalamin metabolism. N. Engl. J. Med 310, 686-690 (1984).

153. Wong, W. Y. et al. Nonsyndromic orofacial clefts: association with maternal hyperhomocysteinemia. Teratology 60, 253-257 (1999).

154. Brenton, D. P., Dow, C. J., James, J. I. P., Hay, R. L. \& Wynne-Davies, R. Homocystinuria and Marfan's syndrome. Bone Jt. J. 54, 277-298 (1972).

155. Paynter, R. A., Hankinson, S. E., Hunter, D. J. \& De Vivo, I. No association between MTHFR 677 C->T or 1298 A---> C polymorphisms and endometrial cancer risk. Cancer Epidemiol. Biomark. Prev. 13, 1088-1089 (2004).

156. Shujuan, Y., Jianxing, Z. \& Xin-Yue, C. Methylenetetrahydrofolate reductase genetic polymorphisms and esophageal squamous cell carcinoma susceptibility: a meta-analysis of case-control studies. Pak. J. Med. Sci. 29 693-698 (2013).

157. He, L. \& Shen, Y. MTHFR C677T polymorphism and breast, ovarian cancer risk: a meta-analysis of 19,260 patients and 26,364 controls. Onco. Targets Ther. 10, 227-238 (2017).

158. Li, X.-L. \& Xu, J.-H. MTHFR polymorphism and the risk of prostate cancer: a meta-analysis of case-control studies. Prostate Cancer Prostatic Dis. 15, 244-249 (2012).

159. Chen, J. et al. A methylenetetrahydrofolate reductase polymorphism and the risk of colorectal cancer. Cancer Res. 56, 4862-4864 (1996).
160. Chen, J. et al. A prospective study of methylenetetrahydrofolate reductase and methionine synthase gene polymorphisms, and risk of colorectal adenoma. Carcinogenesis 19, 2129-2132 (1998).

161. Ulvik, A. et al. Colorectal cancer and the methylenetetrahydrofolate reductase 677C --- > T and methionine synthase 2756A -> G polymorphisms: a study of 2,168 case-control pairs from the JANUS cohort. Cancer Epidemiol. Biomark. Prev. 13, 2175-2180 (2004).

162. Qin, Y.-T. et al. Association between MTHFR polymorphisms and acute myeloid leukemia risk: a meta-analysis. PLoS ONE 9, e88823 (2014).

163. Haghighi, M. M. et al. Association between the 1793G---> A MTHFR polymorphism and sporadic colorectal cancer in Iran. Asian Pac. J. Cancer Prev. 9. 659-662 (2008).

164. Fang, D.-H., Ji, Q., Fan, C.-H., An, Q. \& Li, J. Methionine synthase reductase A66G polymorphism and leukemia risk: evidence from published studies. Leuk. Lymphoma 55, 1910-1914 (2014).

165. Wang, P., Li, S., Wang, M., He, J. \& Xi, S. Association of MTRR A66G polymorphism with cancer susceptibility: evidence from 85 studies. J. Cancer $\mathbf{8}$ 266-277 (2017).

166. Wu, P.-P., Tang, R.-N. \& An, L. A meta-analysis of MTRR A66G polymorphism and colorectal cancer susceptibility. J. Buon. 20, 918-922 (2015).

167. Yuan, L. J. et al. Polymorphisms of tumor-related genes IL-10, PSCA, MTRR and NOC3L are associated with the risk of gastric cancer in the Chinese Han population. Cancer Epidemiol. 36, e366-e372 (2012).

168. Yoo, J.-Y. et al. Association study between folate pathway gene single nucleotide polymorphisms and gastric cancer in Koreans. Genom. Inform. 10, 184-193 (2012).

169. Wu, X. et al. Plasma homocysteine levels and genetic polymorphisms in folate metablism are associated with breast cancer risk in chinese women. Hered. Cancer Clin. Pract. 12, 2 (2014).

170. Zhao, Y. et al. Lack of association between methionine synthase A2756G polymorphism and digestive system cancer risk: evidence from 39327 subjects. PLOS ONE 8, e61511 (2013).

171. Chen, K. et al. Association between genetic polymorphisms in folate metabolic enzyme genes and colorectal cancer: a nested case-control study. Zhonghua Zhong Liu Za Zhi 28, 429-432 (2006).

172. Shi, Q. et al. Polymorphisms of methionine synthase and methionine synthase reductase and risk of lung cancer: a case-control analysis. Pharm. Genom. 15, 547-555 (2005)

173. Cui, L.-H. et al. Folate metabolism-related gene polymorphisms and susceptibility to primary liver cancer in North China. Med. Oncol. 29, 1837-1842 (2012).

174. Semmler, A., Simon, M., Moskau, S. \& Linnebank, M. The methionine synthase polymorphism c.2756A---> G alters susceptibility to glioblastoma multiforme. Cancer Epidemiol. Biomark. Prev. 15, $2314-2316$ (2006).

175. Zhang, F. F. et al. Genetic polymorphisms in folate metabolism and the risk of stomach cancer. Cancer Epidemiol. Biomark. Prev. 16, 115-121 (2007).

176. Suzuki, T. et al. Alcohol drinking and one-carbon metabolism-related gene polymorphisms on pancreatic cancer risk. Cancer Epidemiol. Biomark. Prev. 17, 2742-2747 (2008).

177. Zhang, H., Ma, H., Li, L., Zhang, Z. \& Xu, Y. Association of methylenetetrahydrofolate dehydrogenase 1 polymorphisms with cancer: a metaanalysis. PLOS ONE 8, e69366 (2013).

178. Cui, Y., Jing, Y. \& Sun, Z. Lack of association between MTHFD1 G401A polymorphism and ovarian cancer susceptibility. Tumor Biol. 35, 3385-3389 (2014).

179. da Silva, L. M. R. B. et al. MTHFD1 G1958A, BHMT G742A, TC2 C776G and TC2 A67G polymorphisms and head and neck squamous cell carcinoma risk. Mol. Biol. Rep. 39, 887-893 (2012).

180. Xu, X. et al. B-vitamin intake, one-carbon metabolism, and survival in a population-based study of women with breast cancer. Cancer Epidemiol. Biomark. Prev. 17, 2109-2116 (2008).

181. Mostowska, A., Myka, M., Lianeri, M., Roszak, A. \& Jagodziński, P. P. Folate and choline metabolism gene variants and development of uterine cervical carcinoma. Clin. Biochem. 44, 596-600 (2011).

182. Pawlik, P. et al. Folate and choline metabolism gene variants in relation to ovarian cancer risk in the Polish population. Mol. Biol. Rep. 39, 5553-5560 (2012).

183. Hazra, A. et al. Twenty-four non-synonymous polymorphisms in the onecarbon metabolic pathway and risk of colorectal adenoma in the Nurses' Health Study. Carcinogenesis 28, 1510-1519 (2007). 
184. Chang, S.-C. et al. Single nucleotide polymorphisms of one-carbon metabolism and cancers of the esophagus, stomach, and liver in a Chinese population. PLOS ONE 9, e109235 (2014).

185. Koushik, A. et al. Nonsynonymous polymorphisms in genes in the onecarbon metabolism pathway and associations with colorectal cancer. Cancer Epidemiol. Biomark. Prev. 15, 2408-2417 (2006).
186. Kurzwelly, D. et al. Genetic variants of folate and methionine metabolism and PCNSL incidence in a German patient population. J. Neurooncol. 100, 187-192 (2010).

187. Gao, C. M. et al. Polymorphisms in thymidylate synthase and methylenetetrahydrofolate reductase genes and the susceptibility to esophageal and stomach cancer with smoking. Asian Pac. J. Cancer Prev. 5, 133-138 (2004). 